interactive clinical computer systems, such as that piloted by Weed more than 20 years ago, ${ }^{15}$ may yet come of age.

This work was supported by the Medical Research Council. We thank the midwives in the booking clinic for their cooperation and the consultant obstetricians at St James's University Hospital for allowing us to study women who had been referred to them. We particularly thank Mrs Margaret Barker for her invaluable clerical support, especially in masking the history forms of the first 430 subjects.

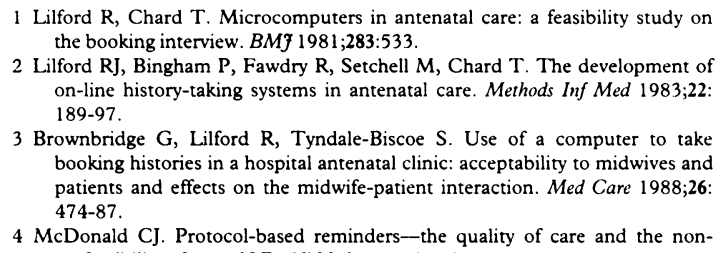
on-line history-taking systems in antenatal care. Methods Inf Med 1983;22: 189-97.

3 Brownbridge G, Lilford R, Tyndale-Biscoe S. Use of a computer to tak booking histories in a hospital antenatal clinic: acceptability to midwives and patients and effects on the midwife-patient interaction. Med Care 1988;26: 474-87.

$4 \mathrm{McDonald}$ CJ. Protocol-based reminders-the quality of care and the nonperfectibility of man. N Engl I Med 1976;195:1351-5.
5 Lilford RJ, Chard T, Bingham P, Carrigan E. Use of a microcomputer network for history taking in a prenatal clinic. Am 7 Perinatol 1985;2:143-7.

6 Guthrie KA, Songane FF, Mackenzie F, Lilford RJ. Audit of medica response to antenatal booking history. Br $\mathcal{Y}$ Obstet Gynaecol 1989:96:552-6.

7 Chng PK, Hall MH, MacGillivray I. An audit of antenatal care: the value of the first antenatal visit. $B M$ F 1980;281:1 184-6.

8 Lilford RJ, Chard TC. The use of a small computer to provide action suggestions in the booking clinic. Acta Obstetrica et Gynaecologica faponica 1984;36:119-25.

9 Staines C. Moving forward in antenatal care-the Sighthill project, Edinburgh. Midwives Chronicle 1983;96:6-8.

10 Lilford RJ, Guthrie K; Kelly M. History-taking by computer. Bailliere's Clin Obstet Gynaecol 1990;4:723-42

11 Quaak MJ, Westerman RF, van Bemmel JH. Comparisons between written and computerised histories. BMF 1987;295: 184-95.

12 Bingham $P$, Lilford RJ, Chard T. Strengths and weaknesses of direct patien interviewing by a microcomputer system in specialist gynaecological practice. Eur 7 Obstet Gynaecol Reprod Biol 1984;18:43-56.

13 Dreyfus HL, Dreyfus SE, Athenafion T. Mind over machine (the power of human intuition and expertise in the era of the computer). Oxford: Blackwell, 1986

14 Gonzalez FA, Fox HE. The development and implementation of a computerised on-line obstetric record. Br f Obstet Gynaecol 1989;96:1323-7.

15 Weed LL. Medical records, medical education and patient care; the problem orientated record as a basic tool. Cleveland, Ohio: Case Western Reserve University Press, 1969

(Accepted 3 September 1992)

\title{
Audit of compliance with antenatal protocols
}

\author{
A F E Yoong, J Lim, C N Hudson, T Chard
}

Abstract

Objective-To assess the implementation of action protocols dictated by antenatal risk factors noted at the initial (booking) antenatal visit.

Design-Retrospective study of 2000 women delivered between 1 March 1990 and 29 March 1991.

Setting-Maternity department of a district general hospital supporting a multiethnic population in inner London.

Main outcome measures-Comparison of clinical actions performed against those dictated by the department's protocols. Analysis according to clinical importance, gestation at booking, maternal age, parity, birth order, ethnic origin, and certainty of gestational age.

Results-Interobserver agreement between the two auditors was good ( $x$ statistic for risk factors detected, 0.78 ; for actions generated, $0 \cdot 80$ ). Of the 15658 actions dictated by department protocols, $3673(23 \cdot 5 \%)$ were actually performed by the clinicians. The 63 combinations of risk factors and actions believed by consultants to be of particular clinical importance had an action rate of $28 \cdot 3 \%$ compared with $18 \cdot 6 \%$ for those considered less important $(p<0 \cdot 001)$. Mothers who first visited the hospital antenatal clinic at or before 24 weeks' gestation had $25 \cdot 2 \%$ of relevant protocols fulfilled $(p<0.001)$. Compliance was significantly improved in women aged 36 or over $(32.4 \%)$, black women $(24 \cdot 9 \%)$, and cases of uncertain gestation $(24 \cdot 5 \%)$. Parity and birth order were not associated with an altered action rate. Ethnic origin deemed as "other" (than white, black, Asian, or oriental) or "unknown" was associated with poor compliance $(19 \cdot 3 \%)$.

Conclusions-Compliance to a set of agreed protocols was poor even though a computer system was available and a protocol manual had been distributed. Protocols were more likely to be implemented in women who booked early and in some groups of women deemed at high risk including older mothers, black women, and those denoted as having uncertain gestational age.

\section{Introduction}

The process of antenatal care and the management of pregnancy is determined largely by the detection of risk factors at the first antenatal attendance (booking visit). The Sighthill scheme promoted a high standard of antenatal care by ensuring that each pregnant woman was formally assessed: features of the pregnancy were noted against a checklist of risk factors; a continuing plan of management using specialist and community services, based on locally agreed protocols, would then be organised and instituted with the help of risk cards.' A similar programme, developed at the Homerton Hospital, used a computer system to help detect obstetric risk factors. ${ }^{2}$ About half of the pregnant women attending the hospital have their booking history collected with this clinical information system; the computer generates a printed antenatal report, in which a list of relevant risk factors appears on the first page. In 1986 a detailed set of protocols for antenatal care was devised. These protocols defined 46 risk factors that could be identified at the booking visit, together with appropriate actions to be followed should a risk factor be found

Two previous studies that analysed medical management according to recorded antenatal information concentrated on the recognition of risk factors at the booking visit rather than the adequacy of the medical response. ${ }^{34}$ In neither study were protocols for specific actions in response to specific risk factors stated to be clearly established before antenatal care was given to the mothers. We evaluated how actions based on the protocol were carried out when risk factors had been identified in mothers booked through the computer system in the maternity department of Homerton Hospital.

\section{Method}

The case notes of 2000 mothers delivered between 1 March 1990 and 29 March 1991 who had been booked on to the computer system at the Homerton Hospital were scrutinised after delivery by one of the authors (AY). The details examined included the booking history and examination and consequent antenatal care. Risk factors were scored as being present or absent or as missing information. Each of 38 possible clinical actions that might be carried out on the basis of risk factors identified at booking were recorded as having been performed or not. Risk factors were said to have been detected if printed on the 
computer antenatal report, hand written into the case notes, or mentioned specifically in correspondence between general practitioner and hospital. It is important to note that risk factors at the booking visit were considered independently of clinical response. For example, advanced maternal age (over 36) would be deduced from the woman's date of birth and date of booking rather than indirectly from the offer of amniocentesis, which might have been performed for other reasons (an abnormal ultrasound scan, for example).

A computer generated random sample of 100 of these case notes was then reviewed independently by another obstetric registrar (JL) for the same features. Four hundred and fifty two differences of opinion were identified between auditors (AY and JL) out of a possible 8400 , giving a discrepancy rate of $5.4 \%$. The $x$ statistic for risk factor detection was 0.78 and that for actions generated was $0 \cdot 80$, indicating good agreement (see appendix)

The ages of the 2000 women ranged from 14 to 52 years (mean (SD) $26.5(5 \cdot 6)$ ). Gravidity ranged from 1 to $17(2 \cdot 8(1.9))$. Twenty five women were carrying twins. Nine hundred and three women $(45 \cdot 1 \%)$ were white, $892(44.6 \%)$ were non-white, and ethnic origin was not specified in $205(10 \cdot 3 \%)$. Two hundred and thirteen women $(10 \cdot 7 \%)$ were not fluent in English; information on this point was not recorded in a further $276(13 \cdot 8 \%)$. Seven hundred and forty two women $(37 \cdot 1 \%)$ booked after 20 weeks; 535 women $(26 \cdot 75 \%)$ were deemed to have an "uncertain" gestation as their booking ultrasound scans were taken after 20 weeks' gestation and their menstrual history was suboptimal.

The protocols were analysed according to gestation at booking, the women's age, parity, birth order, ethnic origin, and uncertainty of gestational age. In addition, protocols were weighted by their perceived effect on clinical outcome. The opinions of five consultant obstetricians were sought; each was asked to score every combination of risk factor and action between 1 and 10, where 1 was thought of as an optional action of no special significance and 10 as an essential action whose omission would constitute serious negligence. This scoring allowed protocols to be divided into two groups according to the median score: those more and those less important.

\section{Results}

Of the 15658 actions dictated by department protocols for the 2000 mothers, $3673(23.5 \%)$ were actually

actors influencing compliance with protocols

\begin{tabular}{|c|c|c|c|c|c|}
\hline & $\begin{array}{l}\text { No of actions } \\
\text { dictated by } \\
\text { protocols }\end{array}$ & $\begin{array}{l}\text { No }(\%) \text { of } \\
\text { actions } \\
\text { performed }\end{array}$ & $x^{2}$ & $\mathrm{df}$ & $\begin{array}{c}\mathrm{p} \\
\text { Value }\end{array}$ \\
\hline Overall performance & 15658 & $3673(23.5)$ & & & \\
\hline \multicolumn{6}{|l|}{ Importance of protocols } \\
\hline More important & 7853 & $2223(28 \cdot 3)$ & $206 \cdot 4$ & 1 & $<0.001$ \\
\hline Less important & 7805 & $1450(18 \cdot 6)$ & & & \\
\hline \multicolumn{6}{|c|}{ Gestation at booking (weeks): } \\
\hline$<24$ & 10082 & $2539(25 \cdot 2)$ & $31 \cdot 3$ & 1 & $<0.001$ \\
\hline \multirow{2}{*}{\multicolumn{6}{|c|}{ Maternal age (years): }} \\
\hline & & & & & \\
\hline$<18$ & 349 & $82(23.5)$ & $125 \cdot 4$ & 2 & $<0.01$ \\
\hline $18-35$ & 12947 & $2824(21 \cdot 8)$ & & & \\
\hline$>36$ & 2366 & $767(32 \cdot 4)$ & & & \\
\hline \multicolumn{6}{|l|}{ Parity: } \\
\hline 1 & 4428 & $1048(23 \cdot 7)$ & $0 \cdot 152$ & 1 & $>0.5$ \\
\hline$>1$ & 11230 & $2625(23 \cdot 4)$ & & & \\
\hline \multicolumn{6}{|l|}{ Birth order: } \\
\hline lst & 2606 & $626(24 \cdot 0)$ & 1.82 & 3 & $>0.5$ \\
\hline 2nd & 3782 & $866(22.9)$ & & & \\
\hline 3 rd & 2888 & $664(23 \cdot 0)$ & & & \\
\hline$\geqslant 4$ th & 6382 & $1517(23 \cdot 8)$ & & & \\
\hline \multicolumn{6}{|l|}{ Ethnic origin: } \\
\hline White & 6809 & $1503(23 \cdot 2)$ & $15 \cdot 76$ & 4 & $<0.005$ \\
\hline Black & 4880 & $1216(24 \cdot 9)$ & & & \\
\hline Asian & 1356 & $301(22 \cdot 2)$ & & & \\
\hline Oriental & 199 & $44(22 \cdot 1)$ & & & \\
\hline Other/uncertain & 866 & $167(19 \cdot 3)$ & & & \\
\hline \multicolumn{6}{|l|}{ Uncertainty of gestation: } \\
\hline Certain & 4804 & $1009(21 \cdot 0)$ & $23 \cdot 25$ & 1 & $<0.001$ \\
\hline Uncertain & 10854 & $2664(24 \cdot 5)$ & & & \\
\hline
\end{tabular}

performed. The protocols least frequently fulfilled $(<1 \%$ of actions) included: (a) screening for systemic lupus erythematosus when there had been a previous stillbirth or neonatal death, a late miscarriage or termination of pregnancy, preterm labour, or when a cervical suture had previously been inserted; $(b)$ the measurement of urea, electrolytes, and uric acid at booking in the presence of proteinuria or when the patient had a history of eclampsia; (c) advice on early admission in labour if there was a history of precipitate labour; (d) organisation of a case conference at 35 weeks' gestation and regular urine chromatography for women who had admitted that they or their partners misused drugs; (e) discussion of epidural anaesthesia with nulliparous women aged over 35 at booking; $(f)$ referral of mothers with proteinuria at booking to the consultant or to a specialist and the formation of a plan of action; and $(g)$ a repeat scan if a significant discrepancy between dates and scan at 16 weeks was noted for mothers with inconsistent uterine size, a cycle length before the last period of over 30 days, a history of oral contraception stopped within three months of the last period, or uncertainty of more than two weeks about the date of the last period.

The only protocol that was followed in $100 \%$ of cases was counselling on drinking alcohol. In heavy smokers (defined as 10 or more cigarettes a day), $94.6 \%$ were advised to reduce their smoking, and placental function was checked in $61 \%$. Placental function tests were carried out in women aged 36 or more $(67.8 \%)$; those with parity $\geqslant 4(64 \cdot 4 \%)$; nulliparous women aged over $35(89.7 \%)$; and women with blood pressure $\geqslant 140 / 90 \mathrm{~mm} \mathrm{Hg}$ at booking $(80 \cdot 0 \%)$. Of women with previous congenital fetal anomaly, $71.4 \%$ were offered an anomaly scan; $70.8 \%$ of women with fetuses at risk from haemoglobinopathy were offered haemoglobin electrophoresis. In all, $68.3 \%$ of women who misused drugs or whose partners were drug misusers and $67.5 \%$ women deemed at risk from HIV were screened for HIV; $63.6 \%$ of those women with a previous cervical suture were referred to a consultant and considered for another cervical suture. Of women found to have a pelvic or abdominal anomaly, $62.5 \%$ were referred to a consultant and had a plan of action organised; $60 \cdot 5 \%$ women with vaginal bleeding had a cervical smear test.

Other compliance rates are of interest. Of women aged 36 or over, $44.5 \%$ had amniocentesis discussed with them, $45 \cdot 2 \%$ had a midtrimester scan, and $40 \cdot 4 \%$ were seen by a consultant between 28 and 32 weeks. Women with a previous stillbirth or neonatal death had their obstetric history validated in $25.5 \%$ of cases, were referred to a consultant in $42.5 \%$ of cases, and had a plan of action made in $44.7 \%$. Of mothers who had had a previous fetus with a congenital anomaly, $14.3 \%$ were offered genetic counselling, $5 \cdot 7 \%$ were offered chorionic villus sampling, and $8.6 \%$ were offered amniocentesis. Previous preterm labour led to referral to a consultant in $23.9 \%$ of cases and consideration of a cervical suture in $5.8 \%$. A history of caesarean section, hysterotomy, or myomectomy led to validation in $41.8 \%$ of cases, discussion of the possible need for operative delivery in $23.4 \%$, and advice on the need to report early in labour in $0.6 \%$. Possible HIV infection in a mother led to screening for other sexually transmitted diseases in only $5 \cdot 5 \%$ of cases.

The table shows that when the analysis was limited to the 63 of the total 126 combinations of risk factors and actions believed by the consultants to be of particular clinical significance the action rate rose to $28.3 \%$. By contrast only $18.6 \%$ of protocols deemed less important were carried out $(p<0.001)$. Similarly, booking at or before 24 weeks' gestation was associated with greater compliance $(p<0 \cdot 001)$. Maternal age at booking was also associated with increased compliance 
$(p<0.01)$, the major difference being accounted for by mothers aged 36 or over. Multiparity and increasing birth order did not affect compliance. The mother's ethnic group affected compliance significantly $(p<0.005)$, with black mothers having more and mothers of unknown or uncertain ethnic origin having fewer protocols performed.

\section{Discussion}

This is the first study in the United Kingdom to look objectively at compliance with existing departmental guidelines in an obstetric unit. In addition, specific factors affecting compliance have been examined. The low compliance echoes a number of other studies related to this topic. For example, primary care physicians at the Brigham and Women's Hospital, Boston, United States, failed to live up to their own recommendations for four of 14 screening procedures. ${ }^{5}$ Guidelines promulgated under the auspices of national medical speciality associations have often failed to stimulate the desired change in practice. ${ }^{6-x}$ Previous audits of obstetric practice in the United Kingdom judged the standard of work in two units according to ideals decided upon retrospectively; although both studies identified significant deficiencies in obstetric practice, no systematic analysis of the factors that could have been associated with these inadequacies was made. ${ }^{34}$

In the present study risk factors and actions were assessed independently. While this is an objective approach, this type of assessment is obviously limited by the overlap between actions for the various risk factors. An action performed in later pregnancy may not necessarily have resulted from a risk factor noted at booking. For example, a request for ultrasonography may be initiated not because of a previous small baby but because of a current problem such as vaginal bleeding. Compliance will thus be overestimated.

It has been suggested that at least two assessors are necessary for audit because of wide interobserver variation. ${ }^{49}$ Such variation can reflect poorly defined protocols which allow a greater degree of subjective opinion, ${ }^{10}$ and there is no evidence that concordance is necessarily more correct than the work of a single auditor. The present study suggests that one auditor is sufficient and that verification, if considered necessary, can be achieved by corroborating a random sample of the main database rather than by duplicating the entire audit. It is probably more important that sufficient time is allowed for accurate data gathering. Indeed, this study was carried out by a full time researcher.

Compliance with protocols may reflect routine rather than selective obstetric practice. At Homerton Hospital, counselling on drinking and smoking was generally performed by midwives and minority health workers. A specially appointed HIV counsellor saw most of the antenatal patients. Blood samples for determining placental function were routinely taken in late pregnancy by the midwives. It is not surprising to find that more protocols were followed if mothers booked early rather than after 24 weeks, when fewer guidelines can be fulfilled. It is also gratifying to note that "more important" protocols were followed more often than "less important" ones. Older mothers and black mothers had a proportionally higher action rate and mothers of unknown or uncertain ethnic origin had a lower action rate. Parity and birth order made no difference to compliance.

Audit demands that standards be set, ${ }^{11}$ and various methods to create practice policies have been described..$^{12} 13$ Low compliance with guidelines may be associated with disagreement or simple ignorance of those guidelines. In the Homerton protocols, for example, not all would agree that nulliparous women aged over 35 at booking should be counselled as to the need for epidural anaesthesia; this probably explains the action rate of $0 \%$. Obviously, there is room for improvement, and this study identifies various areas in which such improvement might be made. Furthermore, compliance of $100 \%$ cannot be expected to occur without coercion and restriction of clinical freedomfor example, the decision to perform amniocentesis could be waived in accordance with the mother's wishes. ${ }^{14}$

Outcome measures (perinatal mortality and morbidity) at Homerton Hospital are similar to national averages for populations with a similar social and ethnic mix, and clinical performance at the Homerton is unlikely to differ significantly from that of other units. Detailed study would probably reveal that many maternity units have low levels of compliance with protocols, should these exist.

We thank the consultant obstetricians at Homerton Hospital for their help and encouragement in this work.

\section{Appendix}

The extent of agreement between observers can be assessed using the unweighted $x$ statistic where all disagreements were arbitrarily regarded as having equal importance. ${ }^{15}$ The $x$ statistic provides a measure of agreement after exclusion of the proportion of agreement expected by chance. It is calculated by the formula $x=P_{0}-P_{e} / 1-P_{e}$ where $P_{o}$ is the observed proportion of agreement and $P_{c}$ is the proportion of agreement expected by chance. The value of $P_{0}$ is calculated by adding the numbers in the congruent cells and dividing by the total number of comparisons made. The components of $P$ are calculated as a proportion of patients assigned to each category by one observer, multiplied by the proportion assigned to the corresponding category by a second observer. The results so obtained in each category are then added and divided by the total number of comparisons to obtain $P_{e}$. Another way of expressing $x$ is $1-q_{o} / q_{e}$ where $q_{o}=1-p_{o}$ and $\mathrm{q}_{\mathrm{e}}=1-\mathrm{p}_{\mathrm{e}} \cdot{ }^{16}$

Kappa can vary from +1 , indicating perfect agreement, to 0 , indicating agreement no greater than expected by chance, and can assume negative values up to -1 when agreement is less than expected by chance. Values over 0.6 indicate good agreement. $^{17}$

1 Boddy K, Parboosingh IJT, Shepherd WC. Schematic approach to prenatal care. In: Royal College of Obstetricians and Gynaecologists Working Party on Antenatal and Intrapartum Care. Report. London: RCOG, 1982:40-6.

2 Carroll S, Chard T, Lloyd DSL, Bradshaw J, Hudson CN, Sloan D, et al. Preparation of risk cards using a computerised obstetric information system. Preparation of risk cards using
fObstet Gynecol 1988;8:222-7.

f Obstet Gynecol 1988;8:222-7.
3 Chng PK, Hall MH, MacGillvray I. An audit of antenatal care: the value of the first antenatal visit. $B M 7$ 1980;281:1 184-6.

4 Guthrie KA, Songane FF, Mackenzie F, Lilford RJ. Audit of medical response to antenatal booking history. Br J Obstet Gynaecol 1989;96:552-6.

5 Woo B, Cook EF, Weisberg M, Goldman L. Screening procedures in the asymptomatic adult: comparison of physicians' recommendations, patients' desires, published guidelines and actual practice. $\exists A M A$ 1985;254:1480-4

6 Lomas J, Anderson GM, Domnick-Pierre K, Vadya E, Enkin MW, Hannah WJ. Do practice guidelines guide practice? The effect of a consensus statement on the practice of physicians. N Engl f Med 1989;321:1306-11.

7 Kosecoff J, Kanouse DE, Rogers WH, McCloskey L, Winslow CM, Brook RH. Effects of the National Institutes of Health consensus development RH. Effects of the National Institutes of Health conse
program on physician practice. $尹 A M A$ 1987;258:2708-13.

8 Grilli R, Apolone G, Marsoni S, Nicolucci A, Zola P, Liberati A. The impact of patient management guidelines on the care of breast, colorectal, and ovarian cancer patients in Italy. Med Care 1991:29:50-62.

9 Barrett JF, Jarvis GJ, Macdonald HN, Buchan PC, Tyrrell SN, Lilford RJ Inconsistencies in clinical decisions in obstetrics. Lancet 1990;336:549-51.

10 Eddy DM. Guidelines for policy statements: the explicit approach. JAMA 1992;263:2239-43.

11 Shaw C. Criterion based audit. $B M 7$ 1990;300:649-51.

12 Eddy DM. Clinical policies and the quality of clinical practice. $N$ Engl $\mathcal{G ~ M e d ~}$ 1982;307:343-7.

13 Eddy DM. Practice policies: where do they come from? fAMA 1990;263: $1265-75$.

14 O'Dowd TC, Wilson AD. Set menus and clinical freedom. BMF 1991;303: 450-2.

15 Cohen J. A coefficient of agreement for nominal scales. Educational and Psychological Measurement 1960;20:37-46.

16 Cohen J. Weighted kappa: nominal scale agreement with provision for scaled disagreement or partial credit. Psychological Bulletin 1968;70:213-20.

17 Brennan P, Silman A. Statistical methods for assessing observer variability in clinical measures. $B M f 1992 ; 304: 1491-4$.

(Accepted 26 October 1992) 